\title{
Reducing Kickback of Portable Combustion Chain Saws and Related Injury Risks: Laboratory Tests and Deductions
}

\author{
Andrzej Dąbrowski \\ Central Institute of Labour Protection - National Research Institute (CIOP-PIB), Poland
}

Portable chain saws are still very dangerous machines. Reduced prices of these machines mean they are widely available to people who like DIY (do it yourself) and professionals. Kickback of chain saws is extremely dangerous for the operator. This paper discusses the results of laboratory investigations of combustion chain saws. The tests were conducted on a standardized kickback test stand and covered the course of kickback, its energy, angle and duration. The results showed that during the contact of a saw chain with wood, the first to appear was the process of wood cutting, which absorbed 90-95\% of the reduced energy of the cutting system. The greater the absorbed energy, the smaller the kickback angle. Wood cutting work is particularly influenced by proper chain tension, the use of chains with anti-kickback links, guide bars with sliding endings and a quickly activated chain brake.

chain saw kickback saw chain kickback energy kickback angle

safe use wood cutting

\section{INTRODUCTION}

\subsection{State of the Art}

Portable chain saws are still basic tools for forest harvesting in many countries. In Poland, $90 \%$ of this kind of work is done with chain saws [1, 2]. Reduced prices of these machines mean they are widely available not only to professionals but also to people who like DIY (do it yourself). Chain saws increase the speed of wood cutting [3, 4], that is why each year over 3 million new chainsaws are sold in the USA. The operation of these newer saws combined with the millions of older chainsaws in circulation results in over 28000 chainsaw-related injures annually [5].

Portable chain saws are very dangerous; their kickback is the greatest hazard related to saw chains as it can cause serious injuries. This extremely dangerous phenomenon is uncontrolled and consists in a sudden movement of the guide bar up towards the operator (Figure 1).

The kickback phenomenon is theoretically described using impact mechanics [7] (Figure 2).

Więsik assumed that chain cutting links hit stationary wood [6]. In the hit point, the temporary force impulse $S$, perpendicular to the guide bar symmetry axis, is created; it causes the chain saw to rotate (Figure 2). A detailed analysis showed that Equation 1 could describe the angular velocity of the chain saw (assuming that the chain saw stopped when there was kickback):

$$
\omega=\frac{k \cdot r\left[J_{\mathrm{s}}\left(\omega_{\mathrm{s}}-\omega_{\mathrm{s} 1}\right)+J_{\mathrm{p}} \omega_{\mathrm{s}}\right]}{J \cdot r_{\mathrm{p}}}\left(\mathrm{rad} \cdot \mathrm{s}^{-1}\right),
$$

where $J$-chain saw inertia towards its temporary rotation point (kilograms square metre), $J_{\mathrm{p}}$-inertia of the chain saw, clutch drum and nose sprocket on

\footnotetext{
This paper was based on the results of a research task carried out within the scope of the first stage of the National Programme "Improvement of safety and working conditions" partly supported in 2008-2010-within the scope of research and development-by the Ministry of Science and Higher Education/National Centre for Research and Development. The Central Institute for Labour Protection National Research Institute was the Programme's main co-ordinator.

Correspondence and requests for offprints should be sent to Andrzej Dąbrowski, CIOP-PIB, ul. Czerniakowska 16, 00-701 Warszawa, Poland. E-mail: andab@ ciop.pl.
} 
the guide bar towards the axis of the crankshaft of the engine (kilograms square metre), $J_{\mathrm{s}}$-inertia of the engine, flywheel and the wheel of the clutch (kilograms square metre), $k$-restitution coefficient, $r$-distance between the temporary rotary axis of the chain saw and the operating line of the temporary force impulse $S$ (metres), $r_{\mathrm{p}}$-radius of the driving wheel of the chain

(a)

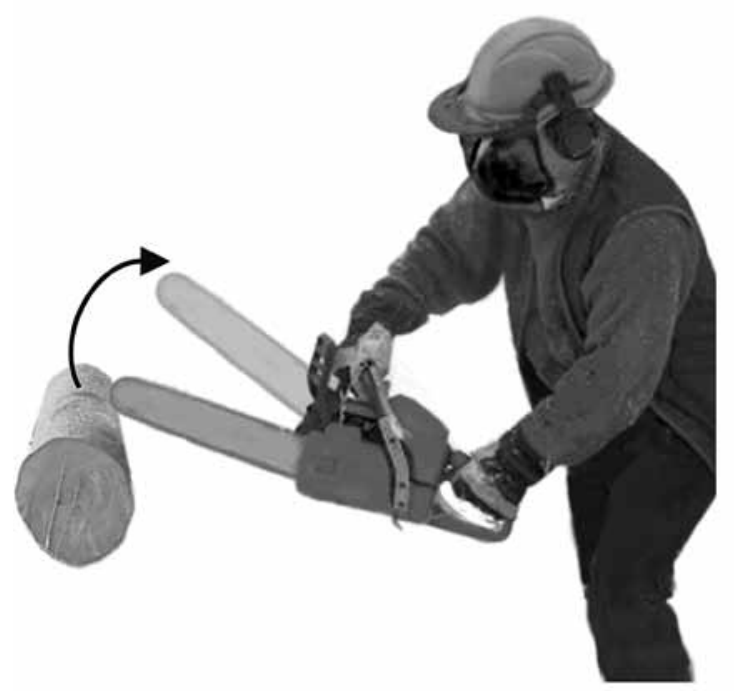

saw (metres), $\omega$-angular velocity of the chain saw after the chain saw links hit wood (radians per second), $\omega_{\mathrm{s}}$-angular velocity of the engine before the chain saw links hit wood (radians per second), $\omega_{\mathrm{s} 1}$-angular velocity of the engine after the chain saw links hit wood which equals the velocity of the disconnection of the clutch (radians per second). (b)
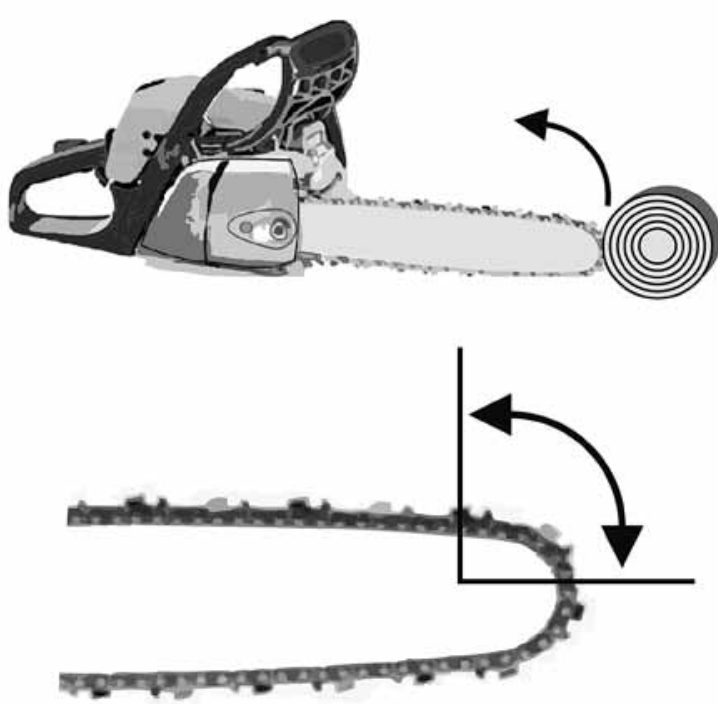

Figure 1. Chain saw kickback. Notes. a-kickback, b-hazardous contact of top part of guide bar with rigid object.
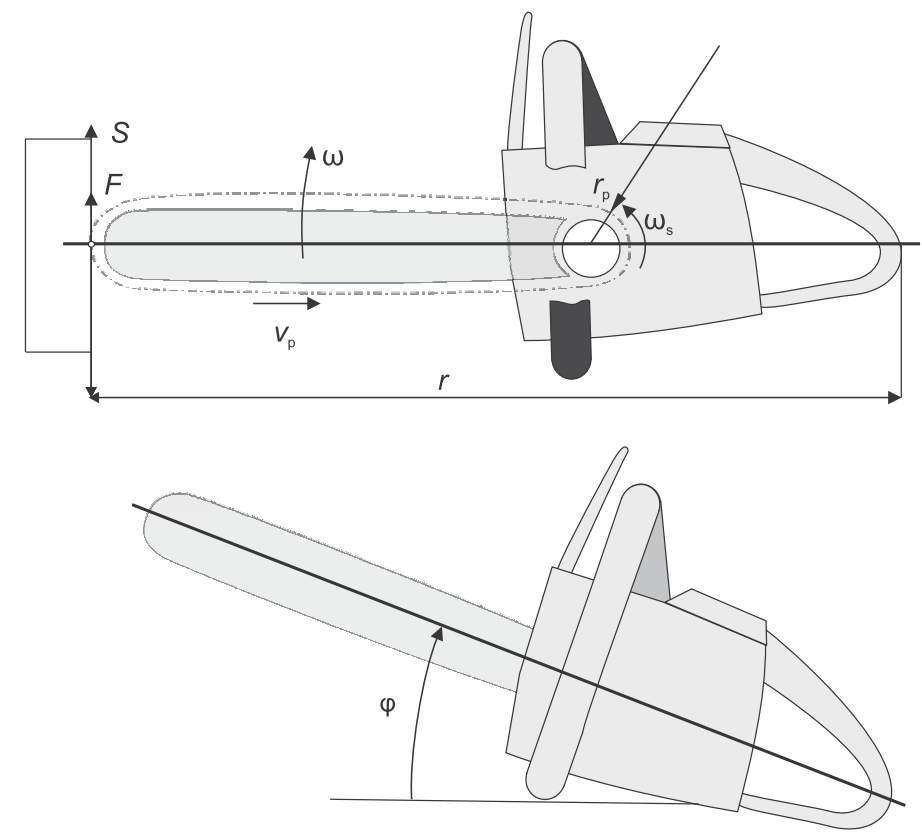

Figure 2. A diagram of chain saw kickback. Notes. F-force, $S$-temporary force impulse, $\omega$-angular velocity of chain saw after chain saw links hit wood, $v_{p}$-linear chain speed, $\omega_{s}$-angular velocity of engine before chain saw links hit wood, $r$-distance between temporary rotary axis of chain saw and operating line of temporary force impulse $S, r_{\mathrm{p}}$-radius of driving wheel of chain saw, $\varphi$-kickback angle $\left(^{\circ}\right)$. 
The energy of chain saw kickback then equals $E_{\mathrm{c}}=\frac{J \omega^{2}}{2}=\frac{1}{2 J}\left(\frac{k \cdot r}{r_{\mathrm{p}}}\right)^{2}\left[J_{\mathrm{s}}\left(\omega_{\mathrm{s}}-\omega_{\mathrm{s} 1}\right)+J_{\mathrm{p}} \omega_{\mathrm{s}}\right]^{2}(\mathrm{~J})$.

Reduction in the kinetic energy of the saw chain and the elements of its driving system (as a result of the saw stopping) is

$$
E_{\mathrm{p}}=\frac{J_{\mathrm{s}}\left(\omega_{\mathrm{s}}^{2}-\omega_{\mathrm{s} 1}^{2}\right)+J_{\mathrm{p}} \omega_{\mathrm{s}}^{2}}{2}(\mathrm{~J}) .
$$

Equation 3 defines the value of maximal energy which can be transferred to the chain saw during kickback.

Standard No. EN ISO 11681-1:2008 [8] requires that combustion chain saws tested according Standard No. ISO 9518:1998 [9] have the kickback angle $\varphi \leq 45^{\circ}$ (Figure 3).

The design of a chain saw affects the risk of kickback. Good design solutions prevent kickback or reduce its effect; moreover, they assure the operator's control of the chain saw. A proper selection of the parameters of chain saw cutting systems essentially reduces kickback-related risk and the kickback angle. On the other hand, an incorrect selection could mean exceeding permissible values of the kickback angle. Personal protective equipment described in the instruction handbooks for these machines also plays a significant role. Its main function is to reduce the effects of potential hazards, i.e., injuries. However, they constitute an additional load for human.

The kickback angle does not depend on the construction of a chain saw only; the way the operator works also influences the extent of the risk. This is the human factor: the operator selects elements of a cutting system and handles the machine.

However, there is no published research on a quantitative analysis of the effect of the parameters of a chain saw on the kickback angle. Manufacturers and certification bodies have few appropriate test stands. They use test results for their own needs only. It is not possible to unequivocally establish what reduces the risk of kickback. Articles have only reported research results on the influence of the technical parameters of chain saws on the efficiency of woodcutting $[10,11]$.

(b)

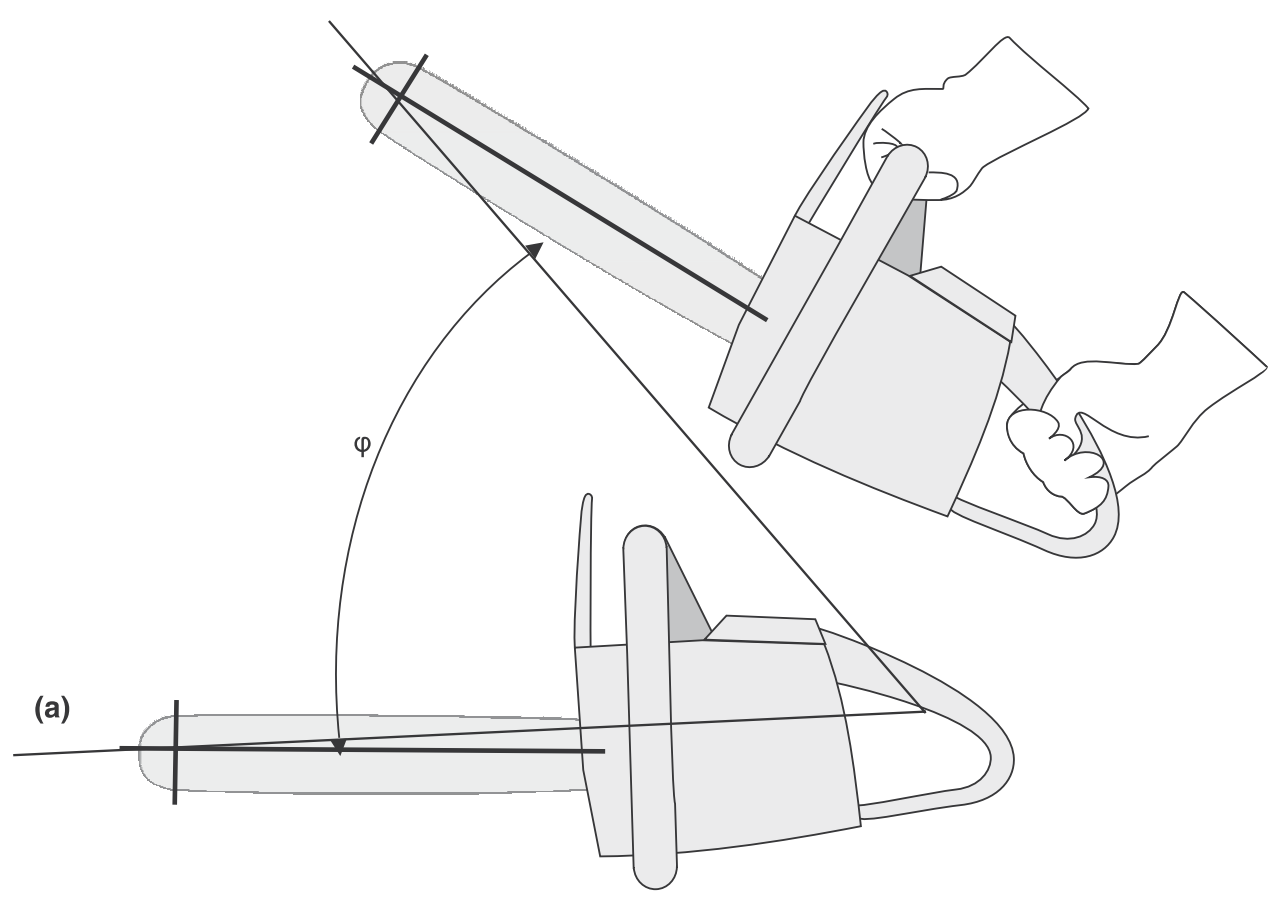

Figure 3. Determining rules of chain saw angular movement according to Standard No. ISO 9518:2001 [6]. Notes. a-initial chain saw position, b-peak chain saw position determined in a mathematical simulation; $\varphi$-computed kickback angle $\left(^{\circ}\right)$. 


\subsection{Research Aims and Hypotheses}

The aim of this research was to study the values of the parameters of kickback and the effect of the design and operation characteristics of chain saws on those values. The design characteristics are engine capacity, the length of the guide bar and the type of tip, the shape of chain links, the pitch and the profile of the chain, the geometry and the type of cutting links and the chain brake. The operation characteristics are blunting of chain cutting links, wearing out of cutting links, chain tension, lowering of the depth gauge and the rotary velocity of the engine.

The research hypothesis was as follows: the effectiveness of anti-kickback precautions that reduce injury risk largely depends on the conditions in which chain cutting links hit wood; they are determined by the characteristics of the cutting system and the operator's behaviour

\section{TESTING METHOD}

\subsection{Equipment for Testing and Calculating Kickback Angle}

A stand for testing kickback was the principal piece of equipment in this study. It had been designed and built in accordance with Standard No. ISO 9518:1998 [6] at Poland's Central Institute for Labour Protection - National Research Institute (CIOP-PIB) (see Dąbrowski [12] for details, Figure 4).

Chain saw kickback energy $\left(E_{\mathrm{o}}\right)$ was calculated according to Standard No. ISO 9518:1998 [9]. The maximal rotation angle of the chain saw (maximal rotary movement energy $W_{\mathrm{r}}$ ) in the cradle and the maximal horizontal back movement of the carriage with a wood kickback test sample (maximal horizontal movement energy $W_{\mathrm{h}}$ ) were considered (Figure 5).

The beginning of kickback followed bringing the engine of the chain saw to appropriate rotary speed and bringing the carriage with a mounted leaning wood kickback test sample forward slowly $\left(v_{\mathrm{p}}=0.76 \mathrm{~m} \cdot \mathrm{s}^{-1}\right)$ towards the tip of the guide bar (angle $\alpha_{\mathrm{p}}$, Figure 6).

Kickback energy was one of the parameters tested on test stands and studied with a computer program for calculating the angle of kickback (Figure 4). The program simulated the motion of a chain saw after kickback (until the saw stopped): rotary (around its centre of gravity), and horizontal and vertical. Other test stands constructed and built at CIOP-PIB, e.g., for

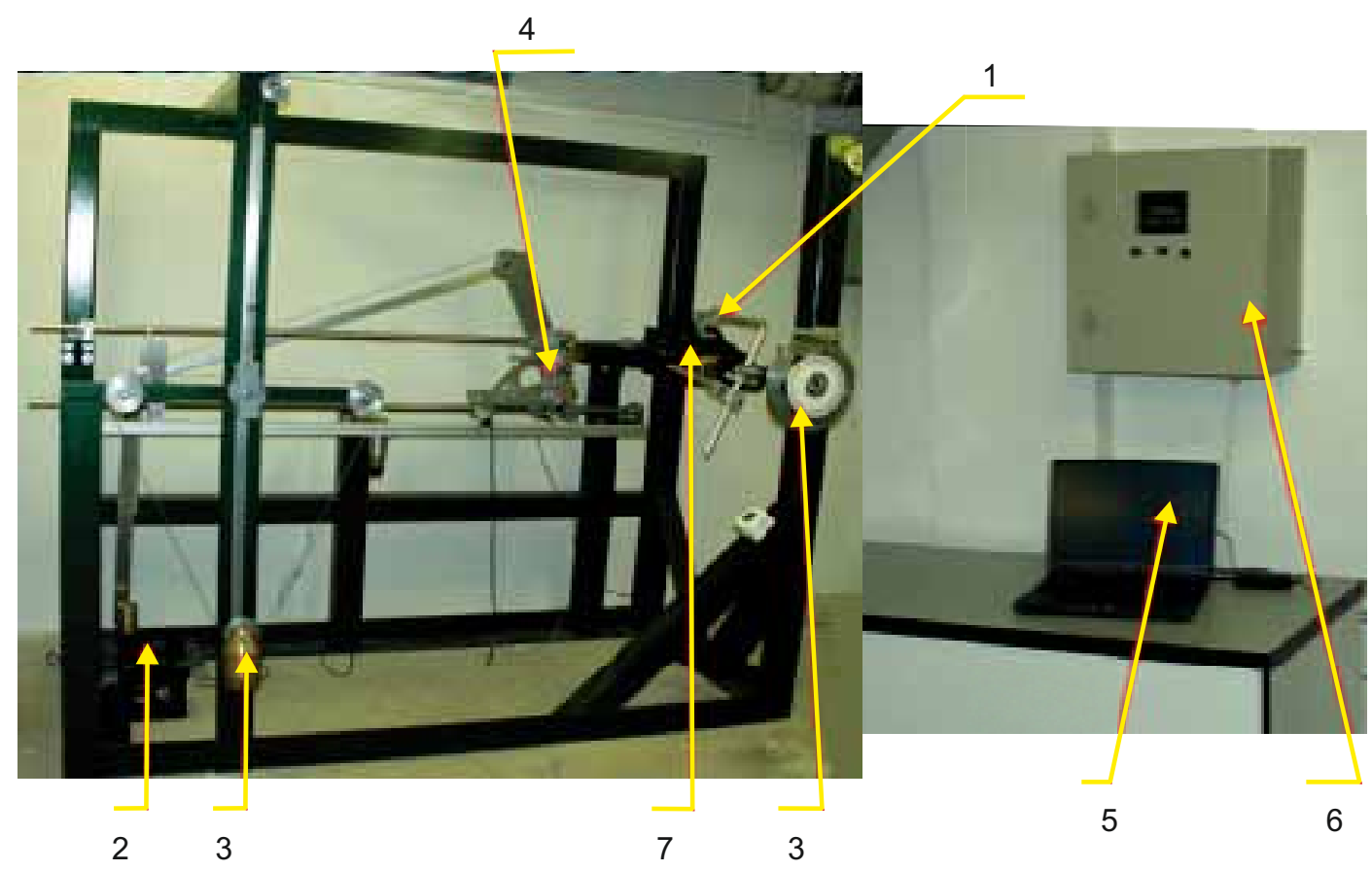

Figure 4. Stand for testing kickback. Notes. 1-cradle with chain saw, 2-carriage-restraining weight with wood kickback test sample, 3-cradle-restraining weights, 4-carriage, 5-control panel, 6-registering device. 


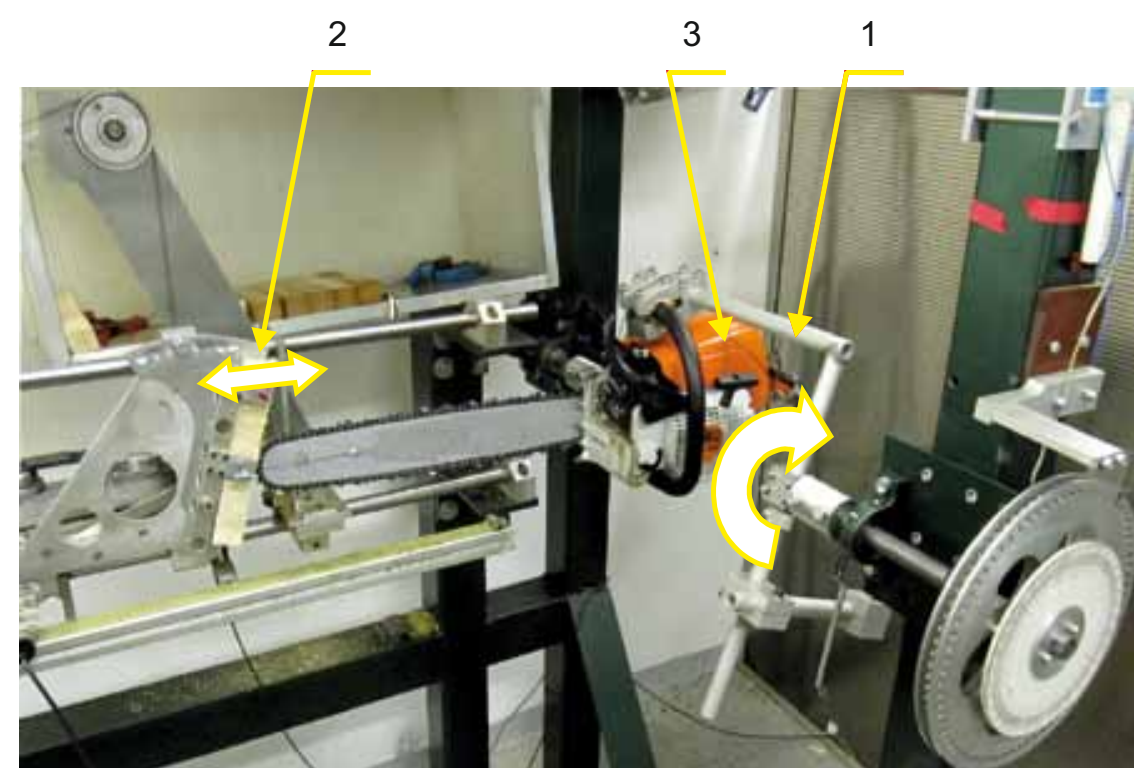

Figure 5. Principle of the study of chain saw kickback (horizontal and rotary movement energy) on test stand. Notes. 1 -cradle with chain saw, 2-wood kickback test sample fixed in mobile carriage moving horizontally to guide bar tip, 3-chain saw.

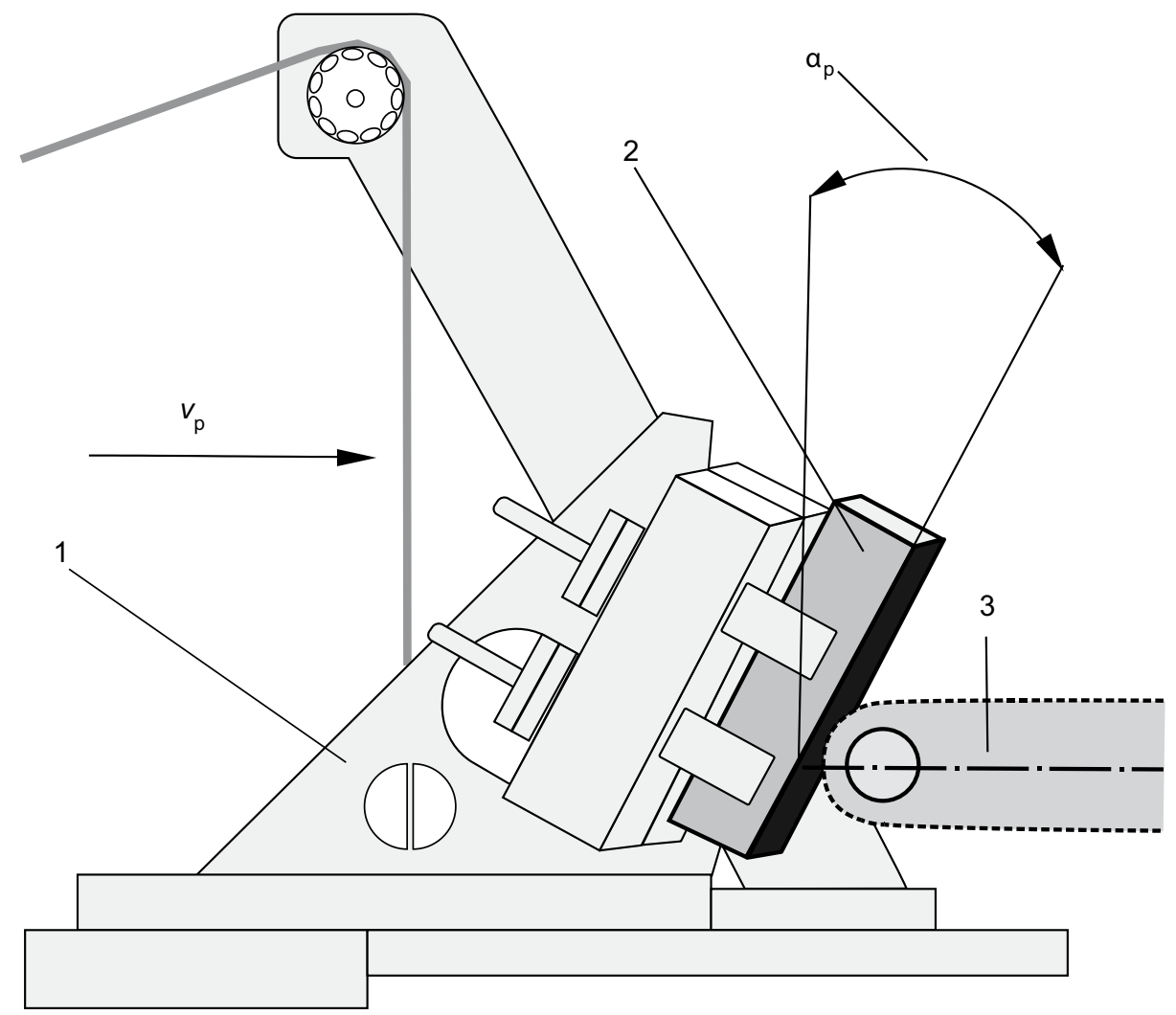

Figure 6. Contact of wood test sample with guide bar tip on kickback test stand. Notes. 1-mobile carriage, 2-wood test sample, 3-guide bar, $v_{p}$-horizontal speed of carriage, $a_{p}-$ contact angle.

testing chain brakes [13], the inertia of a chain saw and the centre of gravity of a chain saw [14] were also used in these simulations and calculations.

\subsection{Chain Saws With Equipment}

Three models of combustion chain saws were chosen for tests and analyses. Their parameters 
represented machines most often used by professional forest workers for forest harvesting. Their basic parameter, i.e., engine capacity, was in the $40-59 \mathrm{~cm}^{3}$ range (for more details see Table 1). Different producers made them, that is why it was possible to test different equipment (saw chains and guide bars), different parameters and different influence on kickback.

Guide bars and saw chains were the interchangeable equipment of the tested chain saws.

TABLE 1. Combustion Chain Saws Prepared for Tests

\begin{tabular}{lcccccc}
\hline & & & \multicolumn{3}{c}{ Rotary Engine Speed (rpm) } & Activating \\
\cline { 3 - 6 } No. & $\begin{array}{c}\text { Engine Capacity } \\
\left(\mathbf{c m}^{\mathbf{3}}\right)\end{array}$ & $\begin{array}{c}\text { Engine Power } \\
(\mathbf{k W})\end{array}$ & $\begin{array}{c}\text { Maximal } \\
\text { Idling }\end{array}$ & $\begin{array}{c}\text { Recommended Length of } \\
\text { Recommended }\end{array}$ & $\begin{array}{c}\text { Alutch } \\
\text { Guide Bar (mm) }\end{array}$ \\
\hline 1 & 56.5 & 3.0 & 2800 & 12500 & 3700 & $330-630$ \\
2 & 40 & 1.9 & 3000 & 13000 & 4300 & 380 \\
3 & 59 & 2.9 & 2700 & 13500 & 3700 & $330-600$ \\
\hline
\end{tabular}

TABLE 2. Guide Bars Prepared for Tests: Their Basic Parameters

\begin{tabular}{|c|c|c|c|c|c|}
\hline No. & Changes in Parameter & Length (mm) & $\begin{array}{l}\text { Groove Width } \\
\text { (mm) }\end{array}$ & $\begin{array}{l}\text { Nose Type/No. of } \\
\text { Teeth }\end{array}$ & $\begin{array}{c}\text { Nose Sprocket } \\
\text { Pitch (in.) }\end{array}$ \\
\hline 1 & none & 400 & 1.6 & nose sprocket/11 & $3 / 8$ \\
\hline 2 & none & 400 & 1.3 & nose sprocket/11 & $3 / 8$ \\
\hline 3 & none & 500 & 1.6 & nose sprocket/11 & $3 / 8$ \\
\hline 4 & fixed nose with smaller radius & 500 & 1.6 & nose sprocket/9 & $3 / 8$ \\
\hline 5 & $\begin{array}{c}\text { removed nose sprocket from tip of } \\
\text { guide bar }\end{array}$ & 500 & 1.6 & sliding/- & - \\
\hline 6 & $\begin{array}{c}\text { fixing of guide bar nose with a } \\
0.325 \text { in. sprocket }\end{array}$ & 500 & 1.6 & nose sprocket/12 & 0.325 \\
\hline 7 & none & 600 & 1.6 & nose sprocket/11 & $3 / 8$ \\
\hline 8 & none & 500 & 1.5 & nose sprocket/11 & $3 / 8$ \\
\hline
\end{tabular}

TABLE 3. Saw Chains Used in Tests: Their Basic Parameters

\begin{tabular}{|c|c|c|c|c|c|c|c|}
\hline \multirow[b]{2}{*}{ No. } & \multicolumn{2}{|c|}{$\begin{array}{c}\text { Angle of Cutting } \\
\text { Edge }{ }^{*}\left({ }^{\circ}\right)\end{array}$} & \multirow[b]{2}{*}{ Cutting Link } & \multicolumn{2}{|c|}{ Depth Gauge } & \multirow[b]{2}{*}{$\begin{array}{c}\text { Mass } m_{p} \\
(\mathbf{k g})\end{array}$} & \multirow[b]{2}{*}{ Other Characteristics } \\
\hline & $\boldsymbol{\theta}$ & $\theta_{1}$ & & Shape & $\begin{array}{c}\text { Lowering } \\
(\mathrm{mm})\end{array}$ & & \\
\hline 1 & 60 & 30 & chisel & lengthened & 0.7 & 0.367 & - \\
\hline 2 & 85 & 30 & semichisel & lengthened & 0.6 & 0.364 & - \\
\hline 3 & 85 & 30 & semichisel & lengthened & 0.6 & 0.298 & thickness of drive link: $1.3 \mathrm{~mm}$ \\
\hline 4 & 85 & 30 & semichisel & lengthened & 0.5 & 0.201 & lower height of saw chain \\
\hline 5 & 48 & 30 & chisel & lengthened & 0.7 & 0.306 & - \\
\hline 6 & 60 & 40 & chisel & lengthened & 0.7 & 0.304 & - \\
\hline 7 & 85 & 30 & semichisel & lengthened & 0.5 & 0.354 & $I_{z}=12.3 \mathrm{~mm}^{*}$ \\
\hline 8 & 60 & 30 & chisel & lengthened & 1.9 & 0.365 & - \\
\hline 9 & 85 & 30 & semichisel & lengthened & 0.6 & 0.364 & $\begin{array}{l}\text { radius of blunting of cutting } \\
\text { edges: } 55 \mu \mathrm{m}\end{array}$ \\
\hline 10 & 85 & 30 & semichisel & lengthened & 0.7 & 0.304 & - \\
\hline 11 & 85 & 30 & semichisel & lengthened & 0.7 & 0.424 & - \\
\hline 12 & 85 & 30 & semichisel & lengthened & 0.7 & 0.394 & anti-kickback tie strap \\
\hline 13 & 60 & 30 & chisel & lengthened & 0.7 & 0.322 & $t=0.325$ in. * \\
\hline 14 & 60 & 30 & chisel & lengthened & 0.8 & 0.304 & - \\
\hline 15 & 60 & 25 & chisel & lengthened & 0.5 & 0.342 & thickness of drive link: $1.5 \mathrm{~mm}$ \\
\hline 16 & 60 & 25 & chisel & standard & 0.7 & 0.341 & thickness of drive link: $1.5 \mathrm{~mm}$ \\
\hline 17 & 60 & 25 & chisel & standard & 0.7 & 0.352 & anti-kickback drive link \\
\hline 18 & 60 & 25 & chisel & standard & 0.5 & 0.362 & anti-kickback drive link \\
\hline
\end{tabular}

Notes. *-see Figure 7. 
Eight guide bar models were studied; they differed in length, width and type of guide bar nose. Table 2 lists their characteristics.
Saw chains were selected according to the 11 features studied (Figure 7). Table 3 lists the characteristics of the 18 saw chains that were

Chain pitch $(t): 0.325-3 / 8$ in. $(8.9-9.5 \mathrm{~mm})$

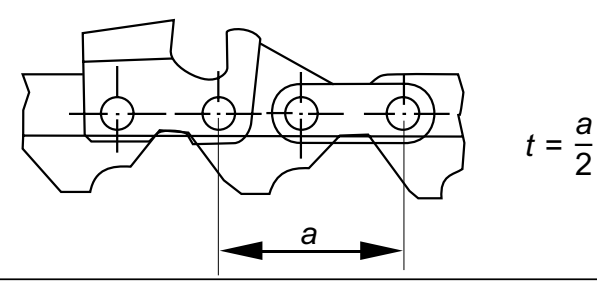

Type of cutting link: semichisel and chisel

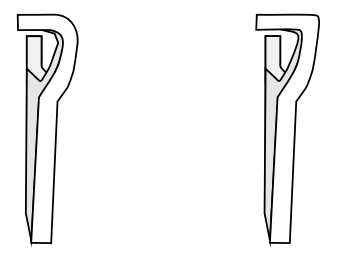

Height of cutting link: standard and lower

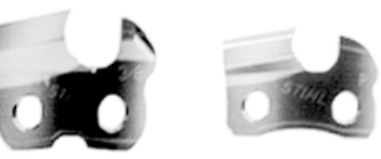

Angle of vertical cutting edge $(\theta): 48^{\circ}, 60^{\circ}, 85^{\circ}$

Angle of horizontal cutting edge $\left(\theta_{1}\right): 25^{\circ}, 30^{\circ}, 40^{\circ}$

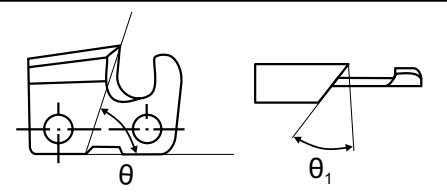

Lowering of depth gauge $(h): 0.5-1.9 \mathrm{~mm}$

Shape of depth gauge: standard and elongated

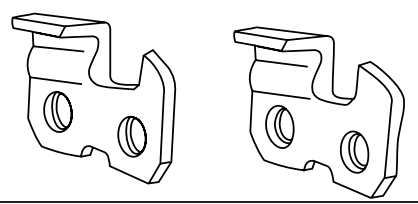

Radius of blunting of cutting links: 10 and $55 \mu \mathrm{m}$

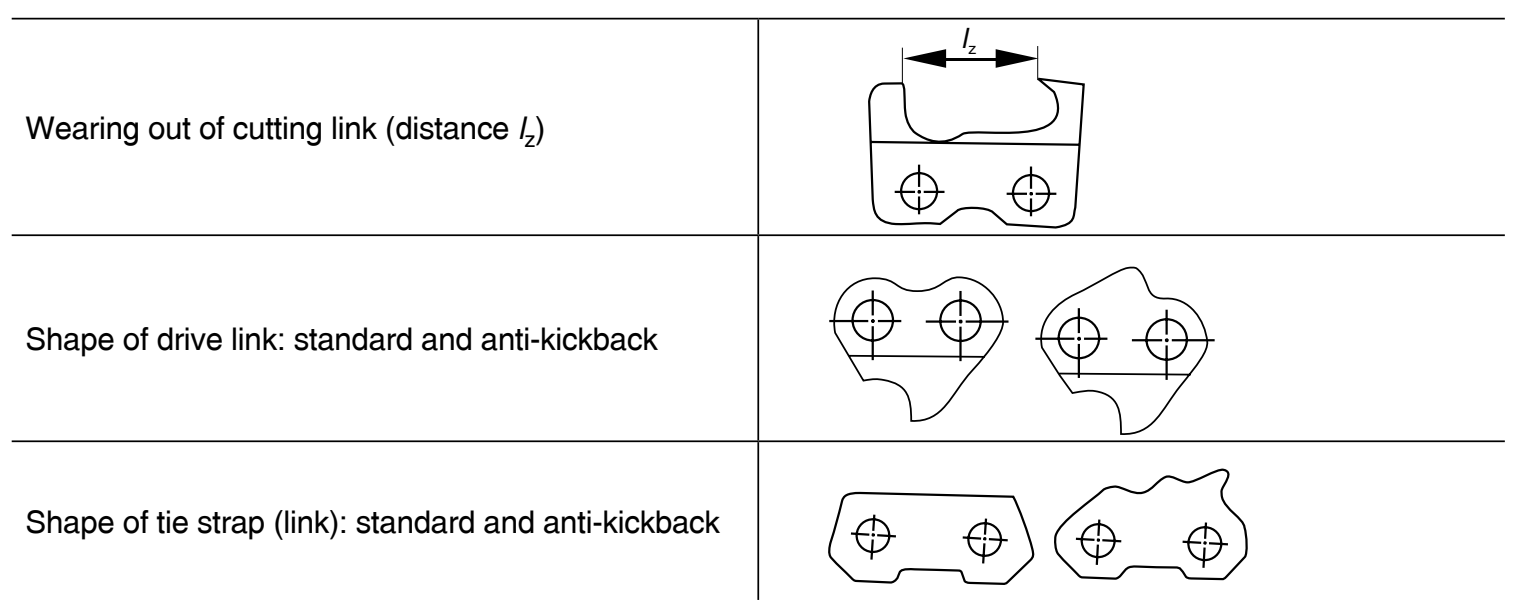

Figure 7. Characteristics of saw chains. 


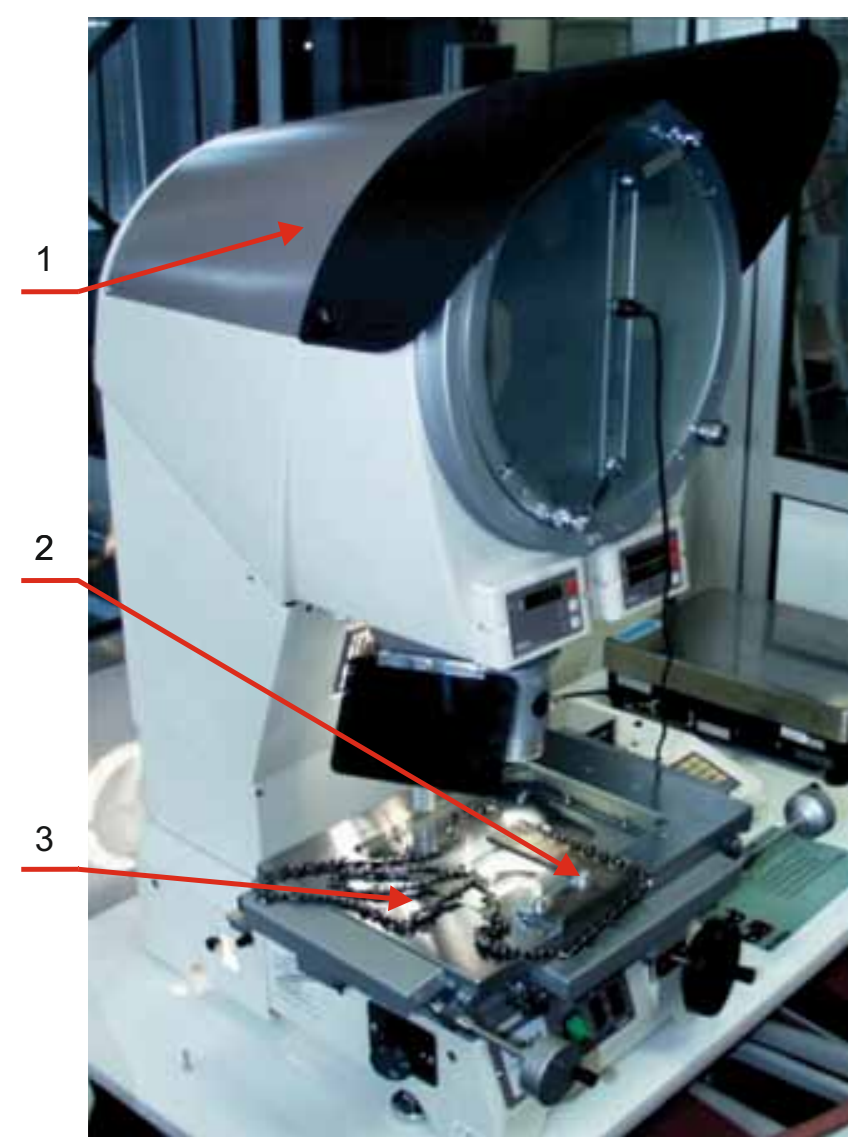

Figure 8. Microscope with projector. Notes. 1-microscope, 2-chain saw holdfast, 3-measured chain saw.

prepared. Changes in the angle of the cutting edges, lowering the depth gauge and blunting cutting links were done on a mechanical whetstone to maintain the parameters of all the cutting links of the saw chain.

A microscope with a projector was used to identify the geometrical features of saw chains (Table 3, Figure 8). Precise measurements of linear and angular parameters were thus possible.

The wood kickback test samples were made of fibreboard (Figure 9). The dimensions $(38 \times 38$ $\times 250 \mathrm{~mm})$, density $\left(732 \pm 32 \mathrm{~kg} / \mathrm{m}^{3}\right)$ and specific cutting resistance with the chain saw $(40 \mathrm{MPa})$ were the parameters [9].

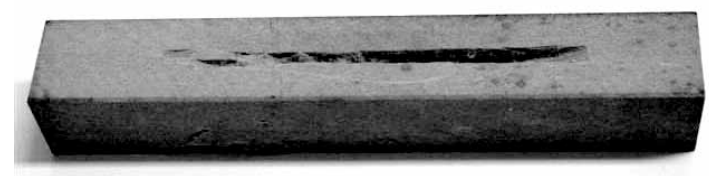

Figure 9. Wood kickback sample after contact with chain, a visible kerf.

\subsection{Characteristics of Cutting Systems}

There were kickback tests for 25 configurations of chain saws and their equipment defining the effect of 18 characteristics of the cutting systems on the kickback angle. The established range of two-variant changes in characteristics was created taking into account knowledge and experience related to the use of chain saws.

The following were studied:

- 11 characteristics of saw chains (Figure 7);

- 4 characteristics of chain saws:

- size of chain saw (engine capacity of 40 and $59 \mathrm{~cm}^{3}$ ),

- operation of chain brake at engine velocity of 150 and $183 \mathrm{~s}^{-1}$ (active and locked),

- velocity of chain saw engine (locked chain brake) of 150 and $183 \mathrm{~s}^{-1}$,

- chain tension (standard and lower),

- 3 characteristics of guide bars:

- length (400, 500 and $600 \mathrm{~mm}$ ), 
- radius of guide bar nose (standard and reduced nose sprocket),

- type of guide bar nose (standard radius, with nose sprocket and sliding).

\subsection{Tools for Quantitative Estimation of Kickback}

The kickback coefficient $k_{\mathrm{o}}$ was used to estimate the value of kickback. It determined the extent of energy absorption by wood, on the basis of the horizontal and rotary motion chain saw energy measured on the test stand and the maximal reduction in the kinetic energy of the chain saw engine and elements of the driving system with the saw chain.

The kickback coefficient $k_{\mathrm{o}}$ was calculated with Equation 4 [15]:

$$
k_{\mathrm{o}}=\frac{E_{\mathrm{o}}}{E_{\mathrm{p}}},
$$

where $E_{\mathrm{o}}=W_{\mathrm{h}}+W_{\mathrm{r}}-$ horizontal $\left(W_{\mathrm{h}}\right)$ and rotary $\left(W_{\mathrm{r}}\right)$ motion chain saw kickback energy (joules), $E_{\mathrm{p}}$-maximal value of reduction in the kinetic energy of the engine and saw chain driving system (joules) (Equation 3). The kickback coefficient $k_{\mathrm{o}}$ indicated the value of the energy absorbed by wood. The lower its value, the more energy was absorbed by wood (Equation 4).

The indicator $\Delta$ was used for quantitative estimation of the effect of the cutting system characteristic on kickback (kickback angle) [15]. The value of the indicator $\Delta$ described the difference between boundary kickback angles for the two variants of the studied chain saw (cutting system) characteristic (parameter) that were compared. Equation 5 was used to calculate the value of $\Delta$ of the proportional intensity effect of characteristics on kickback:

$$
\Delta=\frac{\varphi_{1}-\varphi_{2}}{\varphi_{2}} \cdot 100,
$$

where $\varphi_{1}$ and $\varphi_{2}$ are boundary kickback angles $\left({ }^{\circ}\right)$, obtained from tests of two variants of a characteristic.

The indicator $\Delta$ also made it possible to compare and classify the effect of all studied characteristics on chainsaw kickback. It established the importance of what producers and users do, which is described in literature and in manuals $[16,17,18,19,20,21,22]$. Those instructions are aimed at protecting against kickback hazard.

\section{TESTS}

\subsection{Range and Method}

Tests were done at different angles $\alpha_{\mathrm{p}}$ for each of the 25 test configurations (changes in $\alpha_{\mathrm{p}}$ from $0^{\circ}$ to $30^{\circ}$, every $5^{\circ}$ ) (Figure 7 ). There were three kickback tests for each angle $\alpha_{\mathrm{p}}$ [9]. Horizontal $\left(W_{\mathrm{h}}\right)$ and rotary $\left(W_{\mathrm{r}}\right)$ motion chain saw energy and their average values were measured and calculated. Additional three tests were performed if the difference between energy values and the average energy value exceeded $10 \%$. The test with the maximal kickback energy was used in further studies. The number of tests with different contact angles $\alpha_{\mathrm{p}}$ depended on the test results, usually there were three or four tests. This was sufficient to determine the angle $\alpha_{\mathrm{p}}$ which caused maximal kickback angle. Most tests were done with chain saws with a locked chain brake. Tests with an active chain brake followed kickback tests with a locked chain brake, but only for the angle $\alpha_{\mathrm{p}}$ that previously caused maximal rotary motion chain saw energy $W_{\mathrm{r}}$.

\subsection{Determination of Kickback Angle Accuracy}

The results of tests and other measurements were studied. Thirty entrance quantities that influenced determination of kickback angle uncertainty were identified on their basis [23]. As the process of studying and measuring was complex, a special computer program was developed for that purspose. A detailed study of the effect of the entrance quantities made it possible to determine the uncertainty, which was $\pm 2^{\circ}$.

\section{RESULTS}

The chain saw engine, guide bar length and tip were studied first (Figure 10).

The kickback angle increased with an increase in engine capacity, a shorter guide bar and the 
use of a guide bar nose with a standard number of sprocket teeth. The design of the chain was important, too; the kickback angle increased when there were changes in the standard slope angles of the cutting edges, the depth gauge was lowered and the chain was changed from chisel to semichisel (Figure 11).

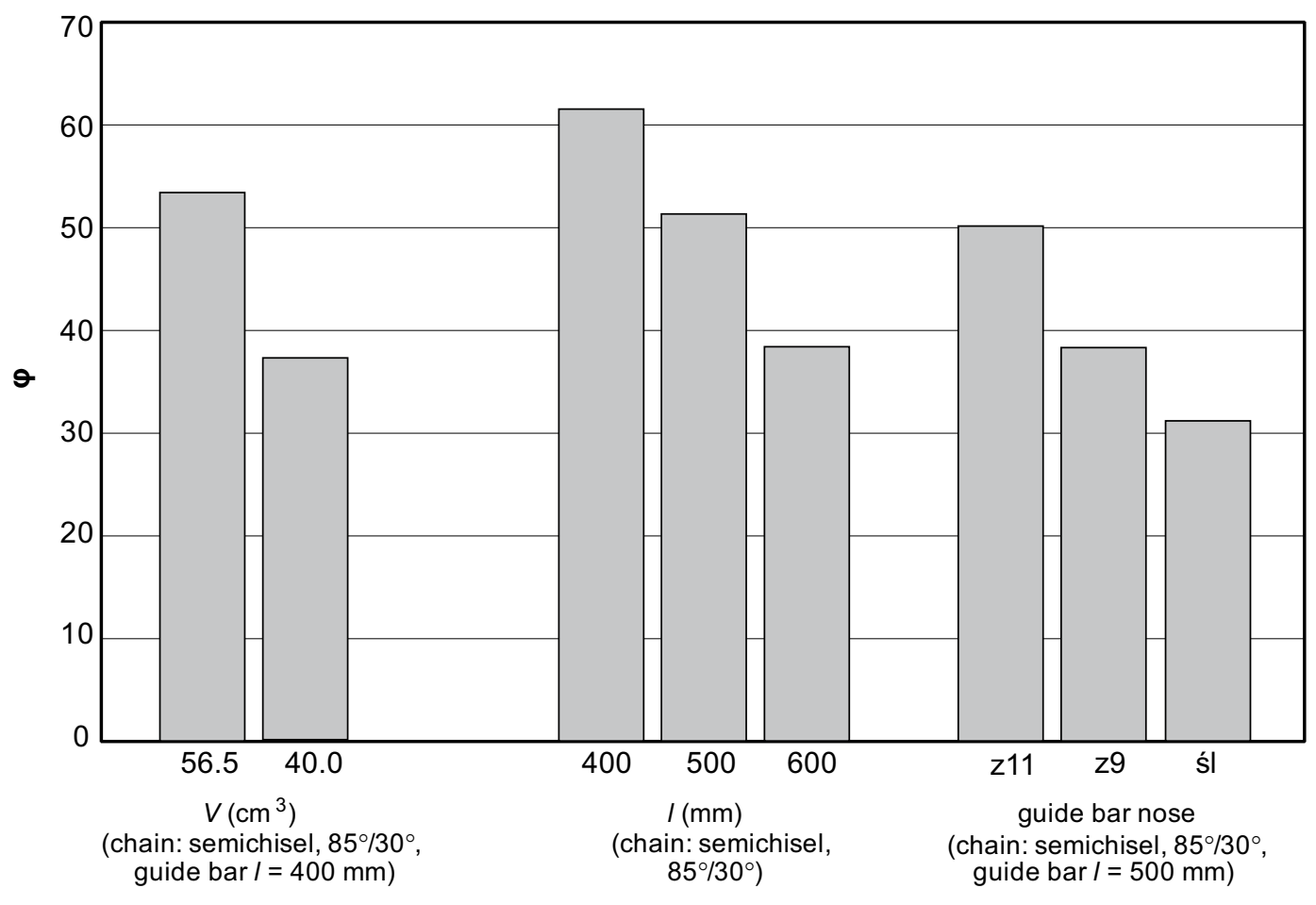

Saw Chain

Figure 10. Effect of engine capacity ( () , length $(I)$ and guide bar tip $(z 11, z 9$, śl) on kickback angle. Notes. $\varphi$-kickback angle $\left({ }^{\circ}\right), z$-number of nose sprocket teeth, śl一guide bar sliding nose.

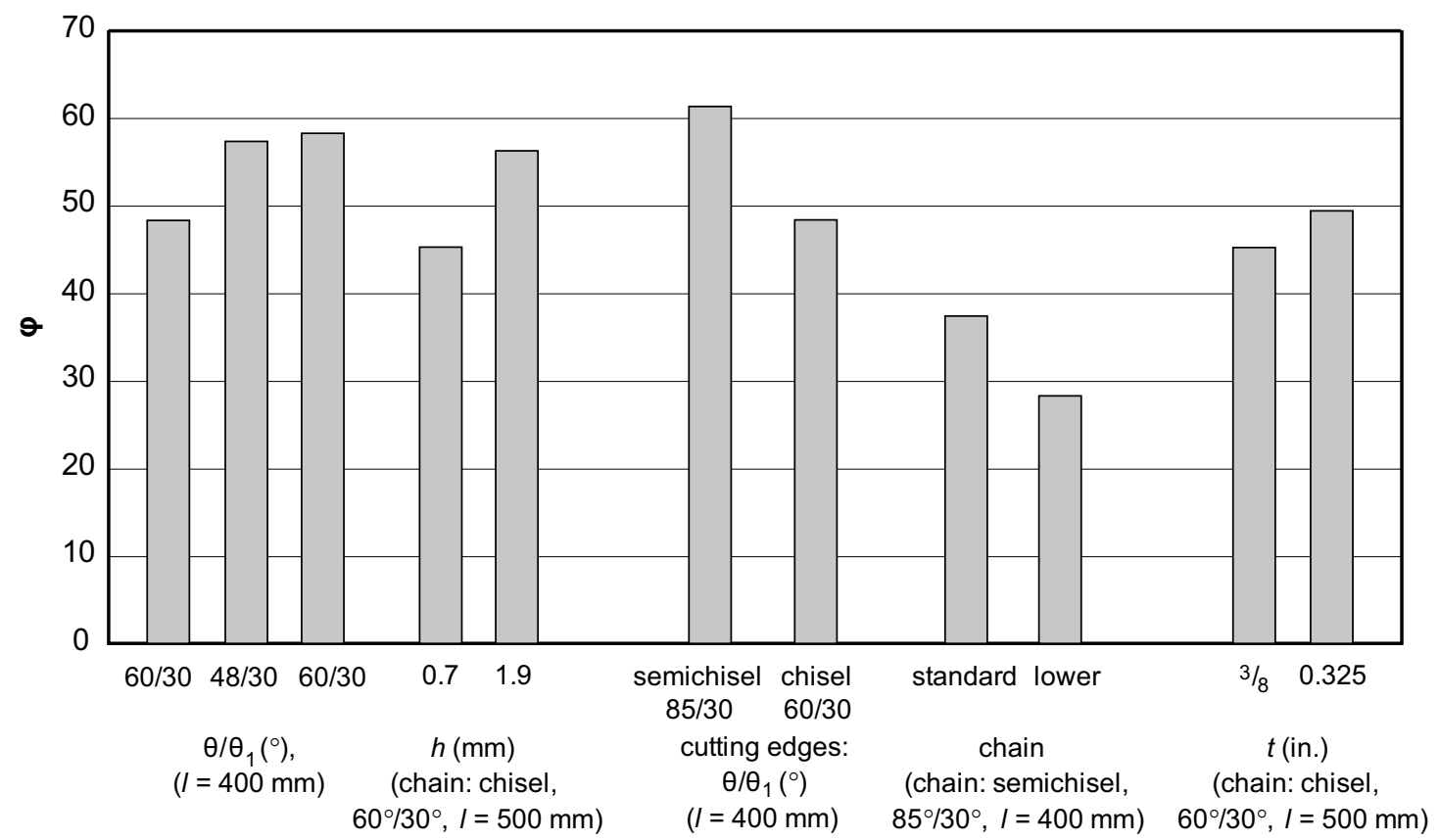

Saw Chain

Figure 11. Effect of saw chain design. Notes. $\theta / \theta_{1}$-angle of cutting edge $\left(^{\circ}\right), h$-lowering of depth gauge, $t$-chain pitch. 
A change in the chain pitch did not cause a significant change in the kickback angle. The effect of the technical condition of the saw chain on the kickback angle was also studied
(Figure 12). Blunting or wearing out by sharpening did not change it significantly. However, a reduction in chain tension significantly increased the angle.

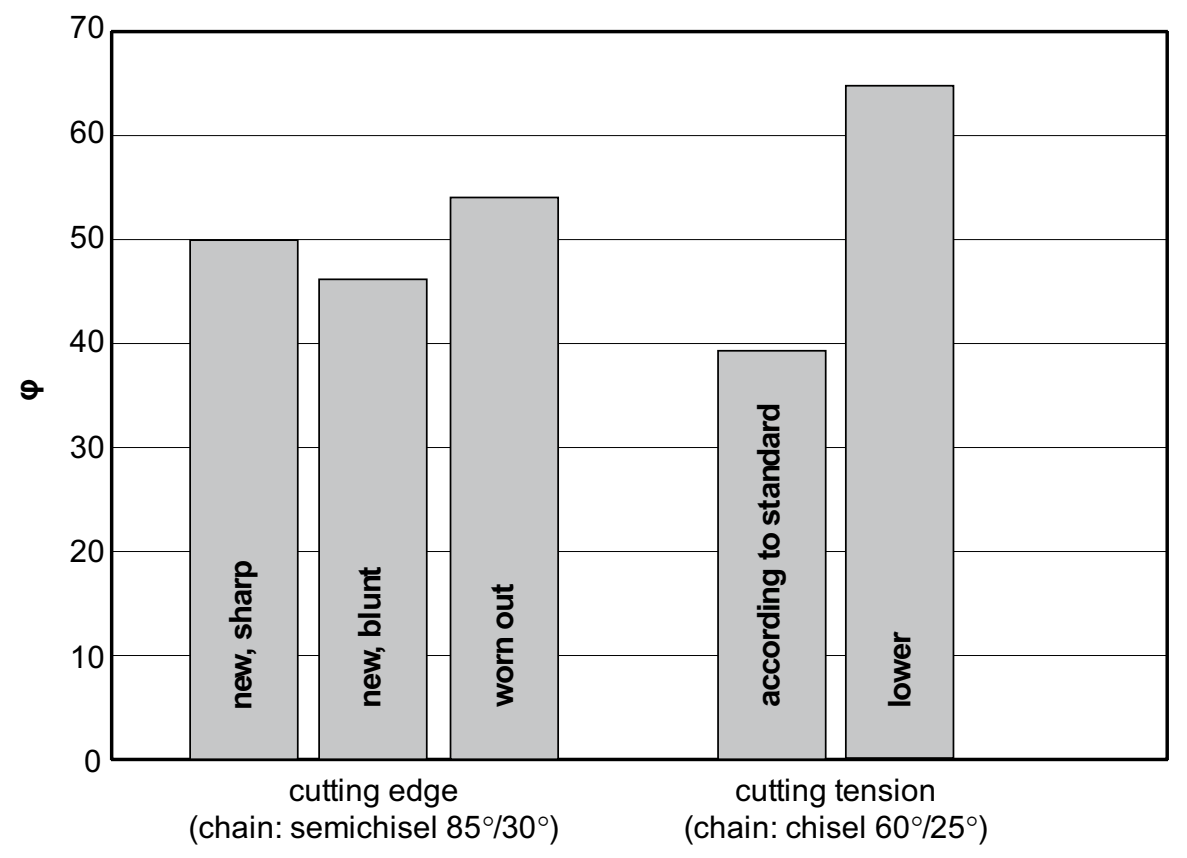

Saw Chain

Figure 12. Effect of the physical condition of the chain $(I=500 \mathrm{~mm})$. Notes. $\varphi$-kickback angle $\left({ }^{\circ}\right)$, blunt-radius of cutting edge $55 \mu \mathrm{m}$; worn out-horizontal cutting edge quite far from depth gauge.

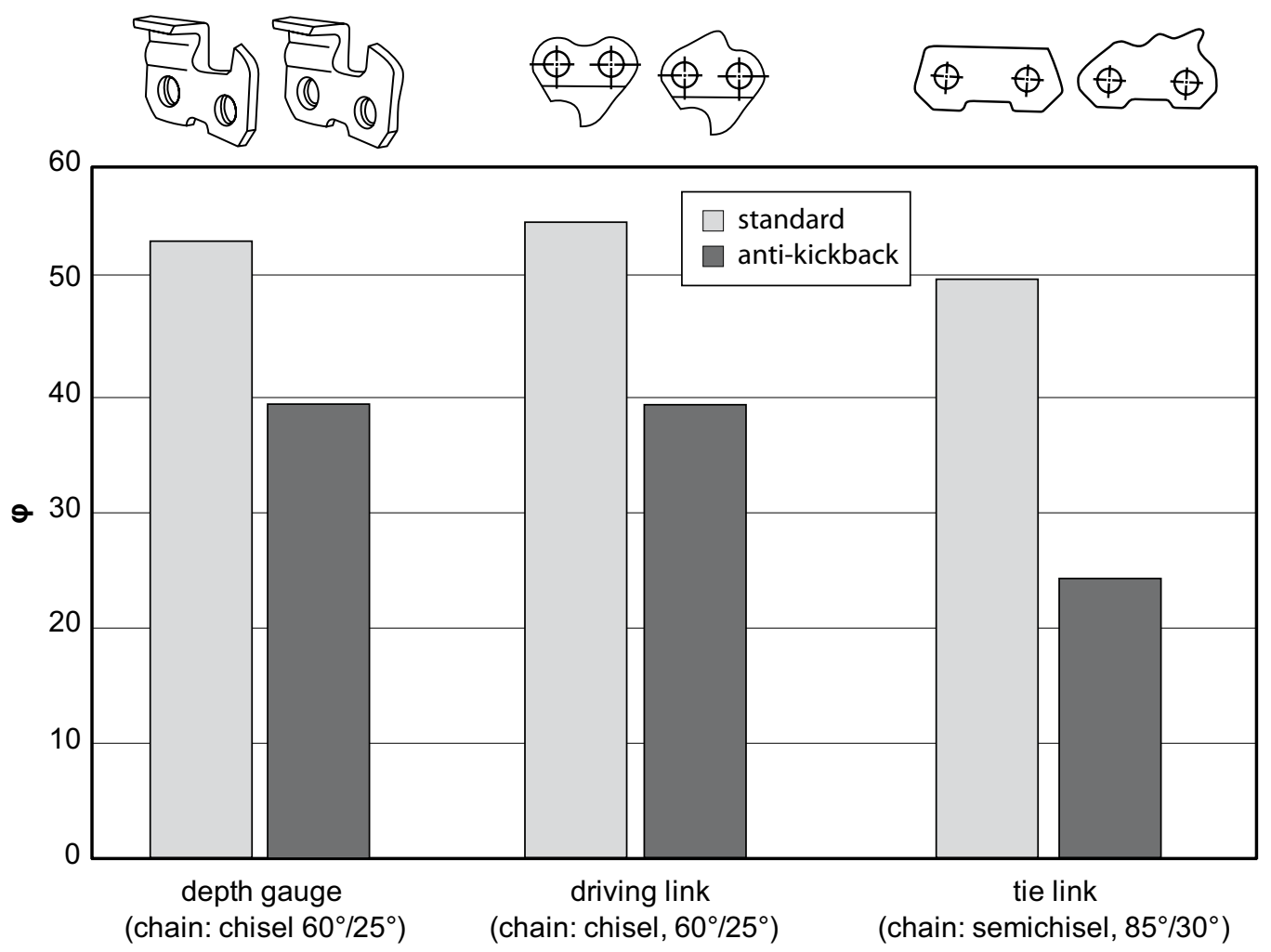

Saw Chain

Figure 13. Effect of chain anti-kickback characteristics on kickback angle $(\varphi)(I=500 \mathrm{~mm})$. 


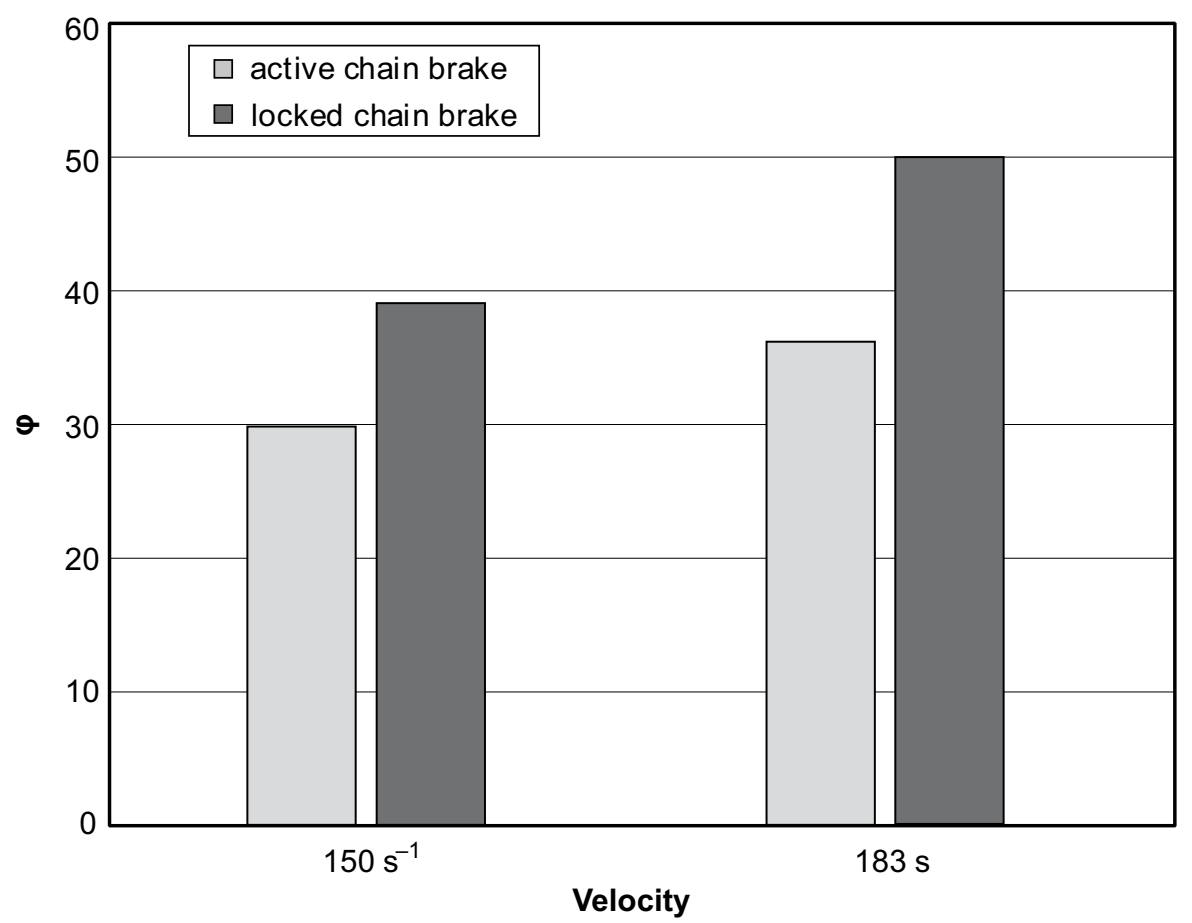

Figure 14. Effect of chain brake and engine velocity on kickback angle $(\varphi)(I=500 \mathrm{~mm})$.

TABLE 4. Indicator of the Effect of a Characteristic of the Cutting System on Chain Saw Kickback $(\Delta)$

\begin{tabular}{|c|c|c|c|c|c|c|}
\hline \multirow[b]{2}{*}{ No. } & \multirow[b]{2}{*}{ Characteristic } & \multicolumn{4}{|c|}{ Kickback Angle } & \multirow[b]{2}{*}{$\Delta(\%)$} \\
\hline & & Variant 1 & $\phi_{1}\left({ }^{\circ}\right)$ & Variant 2 & $\phi_{2}\left({ }^{\circ}\right)$ & \\
\hline 1 & type of cutting link & semichisel & 61 & chisel & 48 & 27 \\
\hline 2 & height of cutting link & standard & 37 & lowered & 28 & 32 \\
\hline 3 & angle $\theta$ of cutting link ${ }^{*}$ & standard & 57 & decreased by $12^{\circ}$ & 48 & 19 \\
\hline 4 & angle $\theta_{1}$ of cutting link ${ }^{*}$ & standard & 58 & increased by $10^{\circ}$ & 48 & 21 \\
\hline 5 & shape of depth gauge & standard & 53 & anti-kickback & 39 & 36 \\
\hline 6 & lowered depth gauge & standard & 56 & increased by $1.3 \mathrm{~mm}$ & 45 & 24 \\
\hline 7 & condition of cutting link & worn out & 54 & new & 50 & 8 \\
\hline 8 & $\begin{array}{l}\text { radius of blunting of cutting } \\
\text { edge }\end{array}$ & sharp chain & 50 & blunt chain & 46 & 8 \\
\hline 9 & length of guide bar & $400 \mathrm{~mm}$ & 61 & $600 \mathrm{~mm}$ & 38 & 60 \\
\hline 10 & radius of guide bar tip & standard & 50 & decreased & 38 & 31 \\
\hline 11 & type of guide bar tip & nose sprocket & 50 & sliding & 31 & 61 \\
\hline 12 & shape of drive link & standard & 55 & anti-kickback & 39 & 41 \\
\hline 13 & shape of tie strap & standard & 50 & anti-kickback & 24 & 108 \\
\hline 14 & chain pitch & $0.325 \mathrm{in}$. & 49 & $3 / 8$ in. & 45 & 9 \\
\hline 15 & size of chain saw & $\begin{array}{l}\text { engine capacity: } \\
59 \mathrm{~cm}^{3}\end{array}$ & 53 & $\begin{array}{l}\text { engine capacity: } \\
\qquad 40 \mathrm{~cm}^{3}\end{array}$ & 37 & 43 \\
\hline 16 & chain brake & locked & 39 & active & 30 & 30 \\
\hline 17 & engine rotary speed & $\begin{array}{l}\text { rotary speed: } \\
10980 \mathrm{rpm}\end{array}$ & 50 & rotary speed: 9000 rpm & 39 & 28 \\
\hline 18 & saw chain tension & decreased & 65 & according to standards & 39 & 67 \\
\hline
\end{tabular}

Notes. *-see Figure 7.

Anti-kickback characteristics of the chain significantly reduced the angle; they were the shape of the depth gauge, and the driving and tie links (Figure 13). The effect of the anti-kickback tie link was particularly visible. The effect of the chain brake increased with an increase in the velocity of the engine (Figure 14). 
The value of $\Delta$ indicates the effect of various characteristics on changes in the dynamic course of kickback (Table 4). The shape of the drive and tie chain link, chain tension, the kind of guide bar nose, the length of the guide bar and the capacity of the engine had the greatest effect on kickback $(\Delta>40 \%) . \Delta=19-40 \%$ for the shape of the depth gauge of the cutting link, the height of the cutting link, the radius of the guide bar tip, the chain brake, engine velocity, the type of the cutting link, the lowering of the depth gauge and the angle of the vertical and horizontal cutting edge. During the tests, the pitch of the chain, the blunting and wearing out of cutting links (as permitted by the manufacturers) were identified as having an insignificant effect on the kickback angle $(\Delta \leq 10 \%)$.

During the tests, the kickback energy was $2-11 \%$ of the kinetic energy of the chain and the chain saw running system before kickback. Most energy was absorbed by the process of cutting wood with the chain. The coefficient $k_{\mathrm{o}}$ changed in the .0204-.1064 range. It had an important effect on the rotation angle $\varphi$ of the chain saw (Figure 3). The angle of kickback was big in tests with maximal values of the coefficient $k_{\mathrm{o}}$. During the tests, the kickback angles were very different and the range of their changes was $41^{\circ}$ (range: $24^{\circ}-65^{\circ}$ ).

In every case, the kickback angle of the chain saw depended on the energy of the rotary motion of the chain saw $W_{\mathrm{r}}$ of $6.8-32.9 \mathrm{~J}$ when the chain saw hit the wood test sample. The energy depended on the specific chain saws characteristics and the conditions in which the cutting links hit wood (Figure 5). The horizontal motion chain saw energy $W_{\mathrm{h}}$ of $0-9.6 \mathrm{~J}$ had a significantly lower effect on the angle of kickback. Its value essentially depended on the angle $\alpha_{p}$ at which the chain links hit wood. A wider angle $\alpha_{\mathrm{p}}$ caused greater horizontal energy. When $\alpha_{p} \leq 5^{\circ}$, the energy of the horizontal motion of the chain saw $W_{\mathrm{h}}$ was generally near zero. The angles $\alpha_{\mathrm{p}}$ of the test samples (Figure 6), which caused maximal kickback angles $\varphi$ (Figure 3) were different (Figure 15), but most often the maximal kickback angles were at $\alpha_{p}=10^{\circ}$.

Depending on the characteristics of the chain saws and the conditions in which the cutting links hit wood, kickback calculated on the test stand, with a locked chain brake, lasted $0.22-0.26 \mathrm{~s}$. In chain saws with an active chain brake, this time was reduced from 0.24 to $0.21 \mathrm{~s}$ or from 0.25 to $0.22 \mathrm{~s}$ (Figure 16).

During the tests, a chain saw with an active chain brake stopped the chain after $0.11 \mathrm{~s}$ (chain stopping time from the beginning of kickback) at $\varphi$ of $23^{\circ}$ and $28^{\circ}$. In those cases, the maximal kickback angles acceptable were $30^{\circ}$ (in $0.21 \mathrm{~s}$ ) and $36^{\circ}$ (in $0.22 \mathrm{~s}$ ), so the chain stopped much earlier than the motion of the chain saw directed at the operator. The results of the tests conducted at a test stand make it possible to make the chain brake cut down kickback time by $\sim 12 \%$.

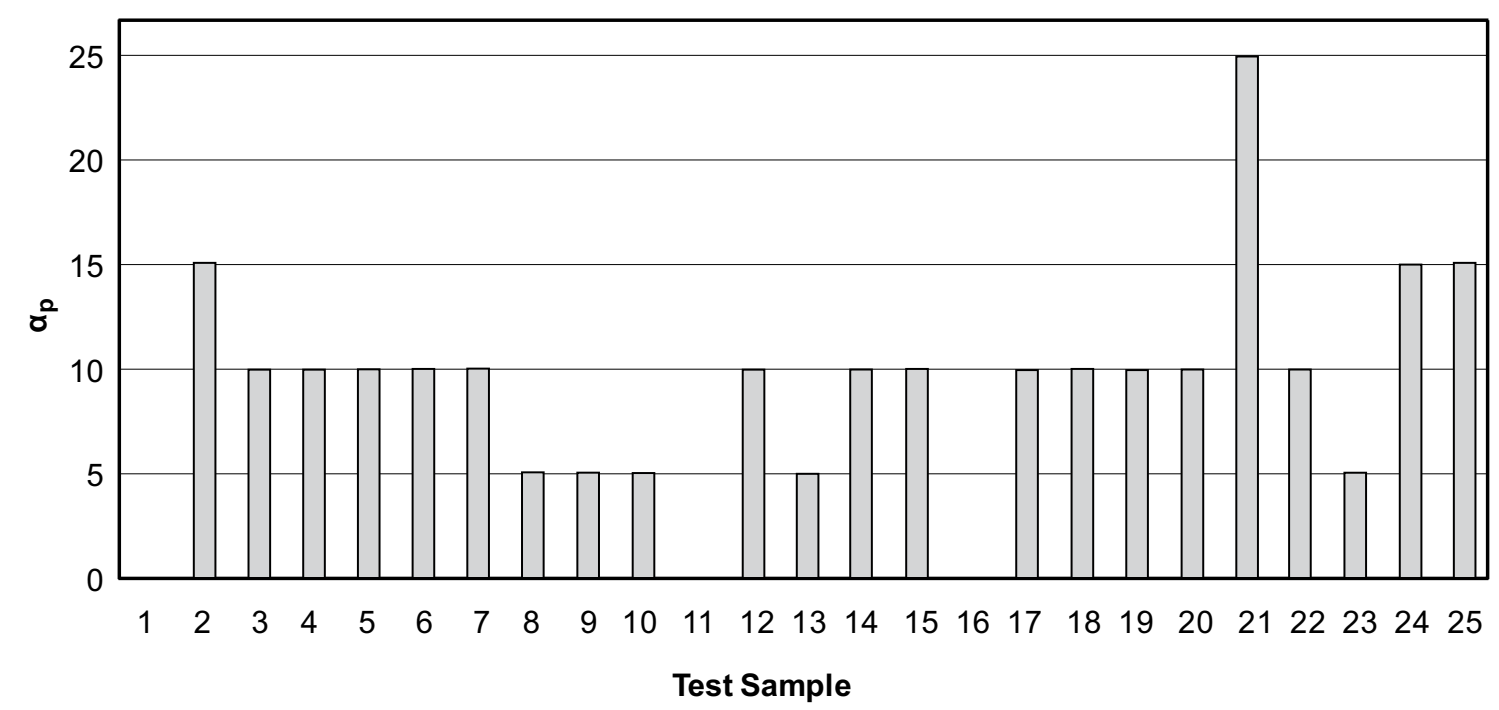

Figure 15. Leaning (contact) angle $\left(\alpha_{p}\right)$ of test samples, causing maximal kickback angle. 


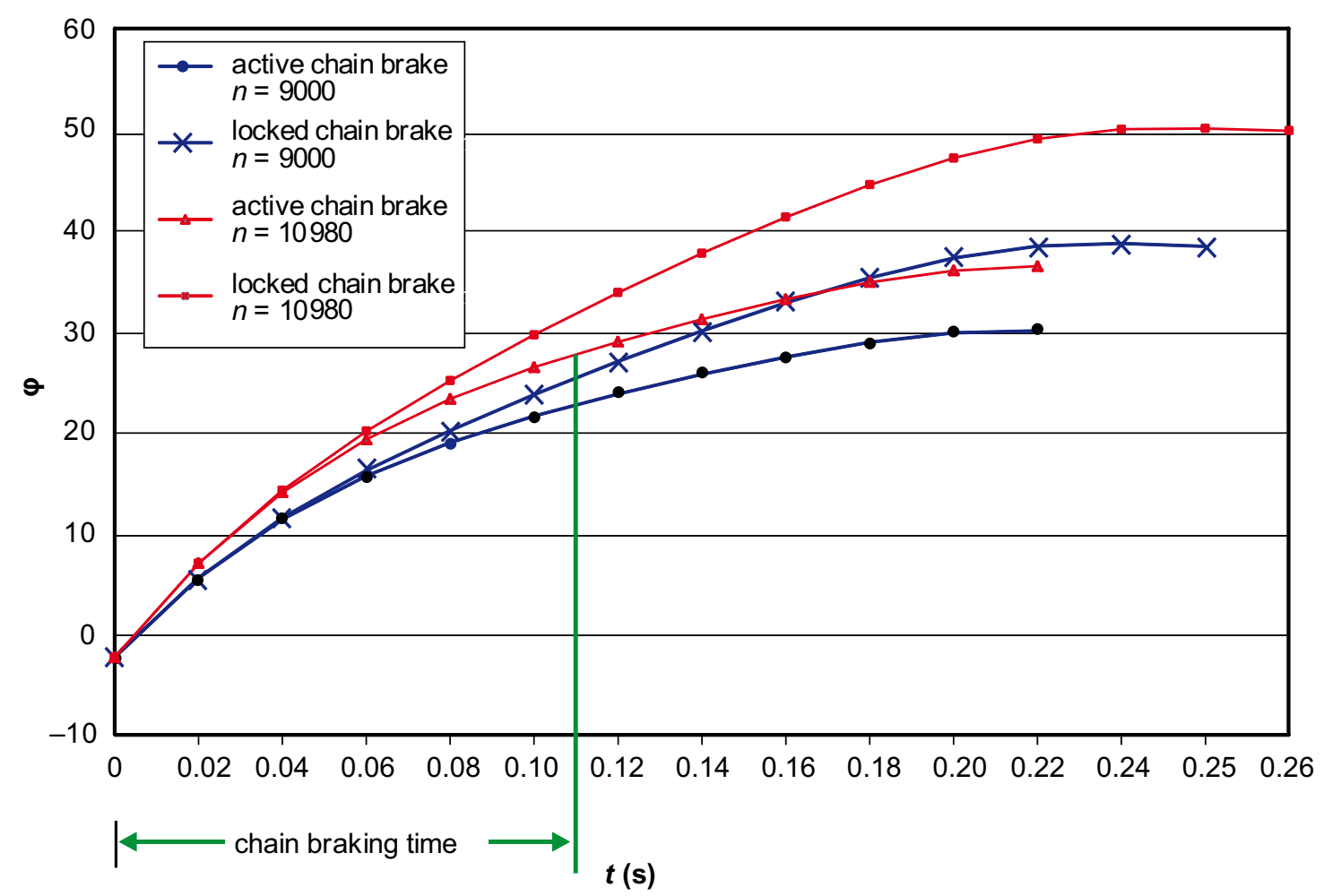

Figure 16. Change in chain saw rotation angle (kickback angle, $\varphi$ ) on the test stand during kickback chain saw study with a 500-mm-long guide bar and a chisel chain: Notes. $t$-duration of kickback, $n$-engine rotation speed at the beginning of kickback (rotations per minute).

\section{DISCUSSION}

Studies confirmed the importance of the designing stage of machines because it reduces the hazard of kickback. Producers can adapt chain saws and their equipment to the needs of different groups of users. Appropriate information on chain saw use is included in manuals and catalogues [17, 24, 25]. Manufacturers provide information on maintaining the parameters of cutting systems (of chains and guide bars) in manuals and instructions on sharpening and maintenance [19].

Manufacturers systematically perform their own tests and put on the market technical solutions that improve the safety of chain saw operators. A new mechanism facilitating the activation of a chain brake is an example [26] (Figure 17).

Test results confirm the importance of a chain brake as a fundamental element in reducing kickback. If this element is missing, the angle of kickback increases by $\sim 30-39 \%$, depending on the increase in the velocity of the engine. The greater the velocity, the greater the safety effect of the chain brake.

The locking of the chain brake caused an increase in the duration of kickback. Duration of kickback of the tested chain saws did not exceed $0.26 \mathrm{~s}$, without an active chain brake, and $0.23 \mathrm{~s}$, with an active chain brake. Chain stopping time was $\sim 0.11 \mathrm{~s}$; in every case the chain stopped much earlier than the movement of the chain saw. This proves the chain brake is effective and useful.

Testing also confirmed that saw chains with anti-kickback elements or guide bars with a reduced radius of the tip protected operators against injuries, especially inexperienced ones.

Work will be safer when new models of chain saws have automatic tensioning of the chain on the guide bar when the chain starts to move. This could be a serious step towards reduced kickback and improved efficiency of woodworking.

Publications on chain saw kickback cover various factors that increase its dynamics and the hazard the operator is exposed to. However, there 


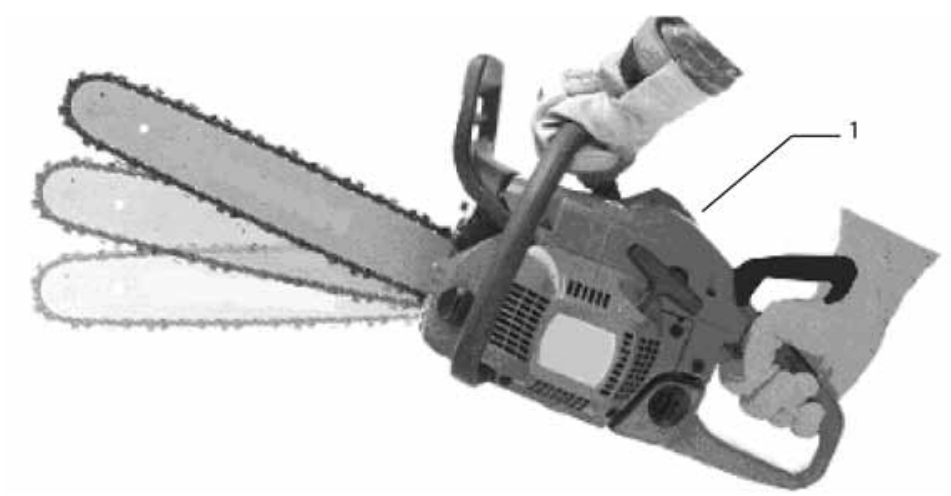

Figure 17. Another way of activating a chain brake. Notes. 1-additional lever for activating the chain brake.

have not been any publications on the quantitative importance of those factors. The wide range of tests and their results have helped distinguish three groups of characteristics of chain saws that affect the increase in and the course of kickback: (a) kinetic energy of the chain and its driving system; (b) inertia of the chain saw; (c) energy dispersion when cutting links hit wood and chain brake activity.

\subsection{Kinetic Energy}

This group of factors consists of the inertia of the engine crankshaft and the elements connected with it either permanently or temporarily, and the inertia of the sprocket (on the nose of the guide bar) and the chain reduced on the axis of the crankshaft and the chain. There is also the rotary speed of the engine: maximal, when the chain hits the wood and the clutch is disengaged when the chain brakes. Bigger chain saws have greater inertia of the rotating elements. In the tested chain saws, the inertia was between $482.8 \cdot 10^{-6}$ and $892.9 \cdot 10^{-6} \mathrm{~kg} \cdot \mathrm{m}^{2}$. These differences meant that a smaller chain saw with the same chain had the kickback angle $43 \%$ lower than a bigger machine. The parameter which essentially decreased the kinetic energy of the rotating elements of the engine and the driving system of the chain is the rotary velocity of the crankshaft at the moment when a chain link hits wood. Kickback tests with the velocity of 9000 and $10980 \mathrm{rpm}$ showed an increase in the kickback angle at greater values of rotary speed. The guide bar has an effect on the kinetic energy of the chain; a longer guide bar increases the mass and energy of the chain.
But lengthening the guide bar causes a simultaneous increase in the inertia of the chain saw. The mechanical model of kickback (Equation 1) demonstrates that the length of the guide bar affects the kickback angle but inversely to the kinetic energy of the chain. Relevant tests demonstrated that the effect of the length of the guide bar was more significant than the kinetic energy of the chain. The tests also demonstrated that a reduction in chain mass by the same length of the chain caused lower kickback angle (e.g., in a low profile link chain).

\subsection{Inertia}

The second group of factors that influences the inertia of the chain saw are the size, shape and location of the elements of the cutting and driving system (handles) but also the guide bar (particularly its length) and the dimensions of the chain. A smaller chain saw (i.e., a smaller capacity of the engine) has lower inertia. A bigger chain saw has bigger elements of the engine and the kinetic energy of the driving system, which are more significant for the dynamics of kickback. That is why smaller chain saws, with the same chain as bigger ones, are safer regarding kickback. This confirms producers' recommendation that nonprofessionals should use smaller chain saws. Tests with guide bars of different length (400-600 mm) unequivocally confirmed the effect of the inertia of the chain saw on the kickback angle. An increase in the inertia caused a decrease in kickback angle. It is necessary to note that lengthening the guide bar to decrease kickback angle also causes bigger energy loss related 
with chain friction in the guide bar. It decreases the efficiency of woodworking and generally impedes the use of the machine. The decision to use a longer guide bar requires thorough consideration.

\subsection{Energy Dispersion}

The third group of factors consists of the pitch and the profile of the chain; the shape of the chain links (cutting, drive and tie); the geometry, the shape and the wearing out of cutting edges; the radius and the type of the guide bar nose; and chain tensioning. Generally, these factors influence the conditions in which the cutting links hit wood. The kickback coefficient $k_{\mathrm{o}}$ characterizes the contact of the chain cutting links with wood. It determines the magnitude of the kinetic energy (of the rotating elements and chain) transferred to the shape of the chain saw when the cutting links hit wood. The tests demonstrate that the values of the coefficient $k_{\mathrm{o}}$ are much lower than one. Energy dispersion caused by the contact of the chain with wood is very high, mostly because a kerf is created (Figure 9). The active part of the energy causing kickback depends on the conditions in which the links hit wood. These conditions mainly depend on the third group of factors. Among the tested factors of this group, the shape of the cutting, drive and tie chain links are very important. Anti-kickback chains with cutting links with a lengthened depth gauge, raising the upper part of tie links or raising drive links reduce kickback angle. When the cutting links on the upper part of the tip of the guide bar hit wood, the anti-kickback chains increase woodworking time and lower the value of the coefficient $k_{\mathrm{o}}$. As a result, the angle of kickback is lower than when chains with standard links are used. However, anti-kickback chains also have an essential deficiency, namely, lower woodworking efficiency. That is why professional operators do not like to use them. Using lower chains has a similar consequence like the shape of the links, but in a lower range. Professionals practically never use this solution. The tests confirmed that the risk of kickback is lower when low chains (instead of standard ones) are used. The tests demonstrated producers' correct choice of the direction of slope angles of the cutting edges of the links. A change in their values would lead to an increase in the angle of kickback. If the slope of the cutting edges change like this, the links cut into wood too rapidly. The chain then stops and kickback is greater. It is also necessary to accept the manufacturers' depth gauge lowering as correct. The test confirmed theory [27] pointing out an increase in the kickback angle when the depth gauge is lowered too much. Excessive lowering of the depth gauge increases woodworking resistance, and makes the chain stop more rapidly when links accidentally hit wood. An important element of the cutting system, which affected the kickback angle, was found in the tip of the guide bar. The tests confirmed that an increase in the radius of the tip resulted in an increase in the kickback angle. However, the result of a test with a sliding tip was unexpected. When this nose was used, the kickback angle was $38 \%$ smaller than when a nose with sprocket teeth with a similar radius was used. Undoubtedly this was the result of a better support of chain links on the sliding nose, which decreased the possibility of the chain cutting links rapidly hitting wood.

Test and study results also confirmed the usefulness of the general mechanical model of chain saw kickback [6] in analysing the effect of basic chain saw characteristics on kickback hazard. This model makes it possible to recognize and analyse many specific chain saw parameters which affect the course of kickback, e.g., the kinetic energy of the mass of the rotating engine and the cutting system, the inertia of the chain saw, the velocity of the disengagement of the clutch. In the theoretical model, set-up kickback energy is greatest when the direction of the links hitting wood is perpendicular to the axis of the guide bar (maximal temporary force is perpendicular to the axis of the guide bar). Tests showed that more the contact of chain links with wood can be more effective at another angle, causing the chain to stop more rapidly. During most tests, the maximal kickback angle occurred at $\alpha_{\mathrm{p}}=$ $10^{\circ}$, the angle at which the tip of the guide bar hit the wood sample. An analysis confirmed the assumption made in the mechanical model that the contact angle of the links with wood that is 
perpendicular to the axis of the guide bar results in vertical movement of the chain saw only and horizontal energy is equal or near zero.

\section{CONCLUSIONS}

Test and study results prove that chain saw operators should pay attention to machine maintenance, in particular to chain tension, systematic correction of the lowering of the depth gauge, the geometry of the cutting links, and the efficiency of chain brake mechanisms. They also demonstrate that chain saw operators can reduce the risk of kickback when selecting machines and their characteristics.

Chain saws are used by different operators, both professionals and occasional users, with different experience and age. There is a wide selection of chain saws on the market, with different engine capacity and equipment. Chain saws can be used in various conditions, e.g., in forests, sawmills, parks, gardens, during accidents and at construction sites. They can be used in forest harvesting and woodworking, when clearing away debris after a storm and in household work.

Inexperienced chain saw operators should realise that their work is casual and reduced kickback is most important for them. They should choose technical solutions that guarantee safety, even if this lowers the efficiency of woodworking. It is necessary to pay attention to certain characteristics of the cutting system, i.e., the design of the saw chain, the capacity of the engine and the type and length of the guide bar. Simple to use devices for chain tensioning are a good solution for inexperienced operators who rarely use a chain saw.

Professional operators, who primarily expect high efficiency, should select machines particularly carefully. The size of the chain saw should be appropriate for the size of the trees that are to be harvested, because the biggest chain saws cause dangerous kickback. The length of the guide bar fixed to the chain saw should primarily depend on the average working conditions and the height of kerfs. A machine with a shorter guide bar offers better flexibility. It is more efficient but carries a higher risk of kickback. Anti- kickback chains are safer but considering higher efficiency and a decreased kickback angle, chisel chains are best for professionals. During professional use, it very often necessary to correct the tension of the chain. This depends on the properties of the lubricating oil, chain blunting, wood hardness and dirt and also on the temperature of the environment. Chain tensioning should be adjusted during work breaks. In winter, they will protect against shrinkage of materials. Because this task if frequently necessary, it could be automated. Producers are considering this solution, which is now implemented in harvester heads.

When operating a chain saw, it is necessary to remember that an increase in engine speed causes an increase in the kinetic energy of the chain saw (of the rotating elements of the engine and of the cutting system). If links hit wood, kickback angle increases, too. That is why it is important to watch the increasing speed of the engine immediately before cutting begins.

Test results demonstrate an essential influence on kickback of chain characteristics maintained by proper sharpening of the cutting tools. Casual users of chain saws should have machines dealers service the chains. Professional users working for a long time in forests, sawmills, parks, gardens, during accidents and on construction sites have to sharpen the chains very often. To maintain the parameters of the chain, equipment recommended by producers should be used; of course, sharpening the machine chain to maintain the parameters of all links is the best solution.

A chain sharpened according to the producers' recommendations until its finally worn out (which is visible on the cutting links) does not cause an essential increase in kickback risk. Test results have confirmed a considerable decrease in the risk of injury caused by contact with the chain during kickback, if a chain brake is used. A chain brake that works well decreases the kickback angle; cutting tools stop much earlier before the motion of the stopping machine is directed up towards the operator. It is very important to systematically check if the chain brake works well.

Research results show that both experienced and occasional operators of chain saws can 
reduce the risk of kickback by selecting proper characteristics of the cutting systems of chain saws and the chain saws themselves but also by their behaviour.

\section{REFERENCES}

1. Dąbrowski A. Guidelines for protection against injuries caused by using portable chain saws for woodworking [unpublished report]. Warszawa, Poland: Central Institute for Labour Protection - National Research Institute; 2002. In Polish.

2. Gendek A. Influence of clutch parameters on combustion chain saw woodworking efficiency [doctoral dissertation]. Warszawa, Polska: Faculty of Production Engineering, Warsaw University of Life Sciences SGGW; 2005. In Polish.

3. Sztyber JF, Wójcik K. Analysis of chain saw operational time during crosscutting of pine bolt assortments. Annals of Warsaw Agricultural University. Agriculture (Agriculture Engineering). 2007;(50):65-9. Retrieved July 10, 2012, from: http://annals-wuls.sggw.pl/files/files/ afe2007no50art11pub.pdf

4. Wójcik K. Analysis of processing operation time and its percent share in timber harvesting with the chain saws. Annals of Warsaw Agricultural University. Agriculture (Agriculture Engineering). 2007;(50):71-7. Retrieved July 10, 2012, from: http://annals-wuls.sggw.pl/files/files/ afe2007no50art12pub.pdf

5. Koehler SA, Luckasevic TM, Rozin L, Shakir A, Ladham S, Omalu B, et al. Death by chainsaw: fatal kickback injuries to the neck. J Forensic Sci. 2004;49(2)345-50.

6. Więsik J. Zagrożenia przy użytkowaniu przenośnych pilarek łańcuchowych do drewna - analiza zjawiska odbicia, sposoby eliminowania lub ogrnaniczania jego skutków [Hazards when using chain saws-analysis of kickback, ways of eliminating or reducing it]. In: Bezpieczeństwo użytkowania przenośnych pilarek łańcuchowych do drewna [Safe use of portable chain saws]. Warszawa, Poland: Central Institute for Labour Protection; 2001. p. 1-12.
7. Leyko J. Mechanika ogólna [General mechanics]. Vol. 2, Dynamika [Dynamics]. Warszawa, Poland: Wydawnictwo Naukowe PWN; 2010.

8. European Committee for Standardization (CEN). Machinery for forestry - portable chain-saw safety requirements and testing-part 1: chain-saws for forest service (Standard No. EN ISO 11681-1: 2008). Brussels, Belgium: CEN; 2008.

9. International Organization for Standardization (ISO). Forestry machinery-portable chain-saws-kickback test (Standard No. ISO 9518:1998). Geneva, Switzerland: ISO; 1998.

10. Maciak A. Effect of wear of saw chain cutters on the rate of wood cutting. Annals of Warsaw Agricultural University. Agricultural Engineering. 2000;(36):21-6.

11. Maciak A. Influence of inclination angle of horizontal cutting edge of the chain saw link on cutting effects. Annals of Warsaw Agricultural University. Agricultural Engineering. 2004;(45):47-52.

12. Dąbrowski A. A study of the hazard caused by fragments of a rotating woodworking tool breaking off [unpublished report]. Warszawa, Poland: Central Institute for Labour Protection - National Research Institute; 2002. In Polish.

13. International Organization for Standardization (ISO). Portable chain-saws-chain brake performance (Standard No. ISO 6535:2008). Geneva, Switzerland: ISO; 2008.

14. American National Standards Institute (ANSI). Safety requirements for gasoline powered chain saws (Standard No. ANSI B175.1:2000). Washington, DC, USA; ANSI; 2000.

15. Dąbrowski A. The effect of selected parameters of the cutting system of a portable chain saw on reducing kickback and related injury hazards [doctoral dissertation]. Warszawa, Poland: Central Institute for Labour Protection - National Research Institute; 2008. In Polish.

16. Oregon $®$. Safety tips. 2000. Retrieved July 10, 2012, from: http://www. oregonproducts.eu/en/support/safety-tips. html 
17. Husqvarna ${ }^{\circledR}$. Instrukcja obsługi [Instruction manual] 357XP/359, No. 1150045-61. Husqvarna; 2005.

18. Oregon®. Product catalog 2003-2004. Portland, OR, USA: Oregon; 2003.

19. Oregon ${ }^{\circledR}$. Instruction manual and safety rules, 1945/04. Portland, OR, USA: Oregon; 2004.

20. Oregon®. Product catalog 2005-2006. Portland, OR, USA: Oregon; 2005.

21. Oregon®. Forestry-saw chains. In: Product catalog 2011-2012. Portland, OR, USA: Oregon; 2011.

22. Oregon ${ }^{\circledR}$. Forestry—guide bars. In: Product catalog 2011-2012. Portland, OR, USA: Oregon; 2011.

23. Dąbrowski A. Determining the effect of selected cutting tools on chain saws kickback hazard. Statutory work. Task III-19. [unpublished report]. Warszawa, Poland: Central Institute for Labour Protection - National Research Institute; 2005. In Polish.

24. Stihl@. MS 299, 310, 390 Assembly, work safety, exploitation, handling and maintenance, 04582095121. M2.G0. Fi. Waiblingen, Germany: Stihl; 2000.

25. Stihl@. Catalog 2005/2006. Waiblingen, Germany: Stihl; 2005.

26. Husqvarna ${ }^{\circledR}$. Husqvarna 353 Trio Brake. Protection system Trio Brake. Catalog chart. Husqvarna; 2007.

27. Stihl ${ }^{\circledR}$. Service training system. Cutting attachments. Waiblingen, Germany: Stihl; 2002. 